\title{
Pedagogy of the Privileged: Globalization, Identity, Belonging, and Empowerment
}

\author{
Jamie Frueh, Ph.D. \\ Professor of Global Politics \\ Director, Center for Engaged Learning \\ Bridgewater College \\ jfrueh@bridgewater.edu
}

\begin{abstract}
For all but a handful of my students, the purpose of studying global politics is to help them succeed in a modern, liberal, globalized society and its structures of privilege. This paper explores ideas for bringing a global perspective into how undergraduates understand themselves and their relative positions in the world. Understanding of discourses of belonging should supplement how we teach discourses of diversity, equity, and inclusion. I draw on critical arguments and insights about pedagogy from Paulo Freire, Antonio Gramsci, and bell hooks to emphasize the political context and power implications not just of the knowledge we as professors convey, but also of the identities that define our relationships to that knowledge and to our students. I confront my own positions of privilege and discuss the implications of the political project of unsettling the complacency with which my students typically approach their own unearned advantages. I argue that discerning and analyzing social and political simplifications is a key component of a liberal education because it frees students to make more decisions with more freedom, which expands and enables real democracy in the long term.
\end{abstract}

In 1968, Paulo Freire published Pedagogy of the Oppressed, an incisive critique of how education is used to entrench the dominant culture into those it dominates. He argued that structures of inequalities persist not just because of the content of what the oppressed are taught, but also because the processes through which their education is delivered has been strategically designed to disempower. He explained mechanisms by which the powerless are constrained, and presented alternatives designed to liberate and empower.

As a professor at a liberal arts college, my goal is also to liberate and empower. My situation differs from Freire's primarily in that the students I teach are not, by global standards, oppressed. This is not to say they are equally privileged. A slight majority of my students identify as female and my classes always contain students who classify themselves as "minorities" in a racial, ethnic, national, or heteronormative sense. While they are all legally adults, age is often used against them. A distribution curve of wealth would show a range comparable to America generally, although students regularly refuse to classify themselves as rich, often claiming any wealth is "my parents', not mine." So my students often feel not just underprivileged, but even, on occasion, oppressed. But from a global perspective, my students are all privileged participants in arrangements of dramatic inequalities of resources, consumption, technology, personal safety, and opportunity. The question driving this paper is how the insights of critical pedagogy apply to the global education of students who are, by global standards, privileged.

While in 1968, Freire adopted a terminology of oppressor/oppressed, I prefer to use the concept of privilege to describe the unequal distribution of unearned goods facilitated by social arrangements that value some characteristics over others. The vocabulary of privilege sidesteps, for 
the purposes of this paper, the question of blame integral to Freire's use of oppression. That said, I acknowledge that, while my students did not initiate these arrangements, they do re-create and reinforce them simply by acting normally and adding to the general perception that such arrangements are normal. This acting is not "an act." For many, if not most, the privileges they enjoy justify the structures of inequality so completely that critical questions about the nature of the social arrangements that support them usually go unasked.

Of course, I am also privileged. I am an American, White, Cisgender, Male, Rich, WellEducated, Tall Professor - who is broadly symmetrical in most of the important ways and still has most of my hair. In addition, my life experiences have made me aware of the position I occupy in the global arrangements of inequality. I am aware of what I am doing when I buy a box of plastic garbage bags at Wal-Mart. I know what it means for my family to take two cars to an event at my son's school in case one of us needs to leave fifteen minutes early. I understand the security provided by my tenured position at a small private liberal arts college in the most powerful country in the world. In my daily life, I benefit from and regularly reinforce systems of privilege and profound inequality.

Perhaps ironically, I also think of myself as working to change the world. I think of my global politics courses as opportunities for undergraduate students to position themselves within communities that span the entire scope of contemporary human experience. When I am successful, my students formulate understandings of and make conscious choices about how to behave towards human difference on a global scale; they understand and evaluate critically the values embedded in the social arrangements that justify the positions they occupy; and they gain tools they may use to construct alternative arrangements. When I am successful, I help the privileged recognize the global nature of their identities in ways that inform decisions they make. The evolution of these identities is a political project, and it should be presented and evaluated as such.

\section{Educating Individuals for a Liberal World}

The project of liberal education is to teach individuals to think and act successfully in a liberal society and give them practice doing so. In contrast to a model of education in which students are rewarded for remembering simplified models that fit neatly into bubbles on an answer sheet, a liberal education is suspicious of simplicity and empowering of individual judgment and creativity, the cornerstones of democratic politics and capitalist economics. Beyond these premises, the definition of a liberal education becomes increasingly disputed. I argue that liberal education should expose the contingent nature of knowledge, teach students the processes by which society determines which competing claims about the world are worthy of being labeled knowledge, and create environments in which students can author their own knowledge claims that they submit to the world for evaluation. From this perspective, it does not matter much what students end up thinking about; the essence of a liberal education is not dependent on particular facts, "great" books, or academic disciplines. Rather, a liberal education requires a pedagogical commitment to providing students with the tools and opportunities to dive below veneers of simplicity and wrestle with the kinds of complexity for which they will be responsible as citizens of a liberal, capitalist democracy. As the politics, economics and culture become increasingly global, so must the complexities that animate a twenty-first century education.

Ontologically, the project of liberal education assumes the liberal individual - a selfconscious (if not necessarily self-interested), reasoning (as opposed to rational), skin-contained chooser who can implement choices by acting. A liberal education should liberate such individuals by teaching them processes of deliberation in order to make them deliberate members of society. It should be empowering because collectively, empowered individuals are supposed to make decisions that turn out over the long term to be best for the community as a whole. A truly liberal social order 
trusts "the people" to sort good (ideas, products, political representatives) from bad. By educating people to see and analyze social and political simplifications, a liberal education should empower them to make more decisions and with more freedom. To the degree that it teaches people to question, evaluate multiple perspectives, and contribute to public discourse, a liberal education has the power to expand and enable critical emancipation and the liberal democratic ideal.

Individuals who deliberate, however, also produce short-term inefficiencies and resistances to existing systems. From the perspective of those with power, goals are usually met most efficiently if individuals reflexively follow established rules and patterns. So the bulk of the American educational system was designed around memorization and repetition.

Education has been reduced to a subsector of the economy, designed to create cybercitizens within a teledemocracy of fast-moving images, representations, and lifestyle choices.... The new hidden curriculum, or "pedagogical unsaid," is the attempt to de-form knowledge into a discreet and decontextualized set of technical skills packaged to serve big business interest, cheap labor, and ideological conformity. (McLaren 2000: 16)

Historically, a truly liberal education has been reserved for elites, and even with the expansion of tertiary education, most Americans still receive an education designed to empower them in only very limited ways (Pfnister 1984, Scheider 2008). While in theory, democracy depends on empowering rational, independently thoughtful and creative individuals, in practice we tend to compartmentalize deliberation, reserving it for particular types of situations and particular people. The result is that students are often surprised by assessment systems and evaluation criteria that demand they think for themselves. Advocates for liberal education often find they must convince potential students, their families, legislators, and society at large of the value of such an agency-laden education.

Freire's pedagogy of the oppressed is designed to do exactly this - expose students to the strategies, justifications and systems that reflexively limit their choices. Like Freire, Antonio Gramsci and bell hooks are similarly concerned with using education to empower those underprivileged by identity systems of class, race and gender. As a student of power and social change, I believe that democracy produces better arrangements if all citizens understand and feel authorized to contribute to the processes that determine the trajectory of their social arrangements. I also believe that an approach to teaching global politics that helps students (privileged or not) develop global identities is an important component of such a contemporary, empowering liberal education.

Identity labels are integral to the distribution of privilege because they are how actors make sense of inequalities - if entities are similar, it would be unjust to treat them differently; if they are different, it would be unjust not to. Students have experiences with the power of identity categories like gender, nation, ethnicity and race in their daily lives and more-or-less-developed theories/intuitions about the systems that undergird them. Exposing students to the global context for these categories of identity/difference provides opportunities for the critical evaluation of the systems that organize privilege in our globalizing world. Talking openly to students about the privileges I have because of my own positions within these hierarchies and pointing out the privileges they reflexively bestow upon me in the classroom demonstrates the local, concrete and pervasive power of social arrangements and, when I am successful, attunes them to such power in other aspects of their lives. Given the privileges that both my students and I enjoy (albeit to varying degrees), such honest and personal discussions about the rules that govern the unequal distribution of power both in the world and in their own lives provide, I argue, the kind of liberal education envisioned by scholars of critical pedagogy. 


\section{Critical Pedagogy}

The term critical pedagogy describes a set of educational practices that seek to empower individuals to change existing social systems. Over the past several decades, authors such as Henry Giroux $(1983,1989,2011)$ and Peter McLaren $(1989,1997)$ have been developing theories of critical pedagogy drawing upon the "emancipation" tradition of critical theory practiced by Horkheimer, Adorno, Marcuse and Habermas. In this same vein, Paulo Freire, Antonio Gramsci and bell hooks discuss how education can be used to promote agency and incite social change. Their ideas have helped me situate myself as an educator of the privileged and cultivate approaches to teaching global politics that emphasize my students' global identities.

\section{Paulo Freire}

Paulo Freire argues the right educational environment can inspire students to act in ways that change the world. Initially developed though his work among the underprivileged and powerless in northeast Brazil, Freire's pedagogy is designed to enable such students to understand how existing social arrangements work to their disadvantage and to actualize their creative agency for change (McLaren 2000). For Freire, such realizations will only be liberating if they are "forged with, not for, the oppressed" (Freire 1968, 33). The system cannot be explained to the oppressed, who will only be empowered if they discover their oppression on their own through dialogue. Once the oppressed understand how they participate in the system that oppresses them, they will find within themselves the ability to change those relationships and build true democracy, which they alone can create.

Practically, Freire's teachers must play nothing more than a facilitating role. Freire condemns a "banking" concept of education, which treats students as receptacles to be filled. "Instead of communicating, the teacher issues communiqués and makes deposits which the students patiently receive, memorize and repeat" (Freire 1968, 58). As an alternative, Freire advocates "libertarian education" in which the contradiction between student and teacher is resolved by making both teachers and both students (Freire 1968, 59). He seeks to empower his students and to inspire thought. Knowledge can only help Freire's oppressed overcome the "contradiction in which they are caught" (Freire 1968, 34) when it motivates them to action.

While his faith in the liberating potential of an empowering education is inspiring, it needs to be adapted if it is to apply to the education of students born into privilege, whom Freire considers oppressors. Freire argues that the privileged cannot participate in the planning of a new society, even if they become aware of the "dehumanizing totality" in which both they and the oppressed are trapped $(1968,32)$. He has empathy for the "considerable anguish" individuals who are privileged feel upon learning of their role in the system $(1968,34)$. However, for Freire, even benevolent help is paternalistic and dehumanizing, and any attempts they make to transform the system are inherently self-defeating $(1968,42)$. The practical implication is that my privileged students should not participate in politics and the education I provide them should not empower them to do so, at least until the oppressive system is eliminated.

I admire Freire's commitment to freedom and democratic change, but (from my position of privilege) I find these implications untenable and shortsighted. Freire oversimplifies social power relations by reifying power along a single social cleavage - class. Despite strict prescriptions about allowing understanding of oppression to come up from the oppressed themselves, Freire already knows the conclusions to which they should come. His anecdotes about oppressed being liberated are about people articulating ideas that agree with Freire's own interpretation of the system. This same level of certainty about class oppression is evident in the works of Antonio Gramsci, who also claimed to have a firm understanding of the causes and dynamics of oppression. Gramsci, however, has more faith in the liberating power of empowering education for all. 


\section{Antonio Gramsci}

Antonio Gramsci, an Italian communist jailed by Mussolini in the 1920s, wrote prolifically about Marxism and Italian politics while in prison. Gramsci's Prison Notebooks (1971) are credited with infusing the Marxist tradition of historical materialism with a powerful understanding of how social ideas constrain people's understanding of reality and therefore their acts in the world. His concepts of hegemony, common sense and the organic intellectual all have important implications for contemporary Marxist, post-structuralist and constructivist thought, including for arguments about global politics.

Gramsci also wrote about education in a very practical sense, commenting upon a series of contemporary educational reforms. Despite his Marxism, Gramsci was a vocal advocate of a liberal education for everyone. While his work has been appropriated by advocates of standardized western-oriented curricula, rigid classroom rules and authoritarian discipline (Entwistle 1989; Hirsch 1996), these authors misread Gramsci's underlying emancipatory project (Giroux 1999). Gramsci condemned a system that relegated "instrumental classes" to a "vocational" education "designed to satisfy immediate, practical interests" (Gramsci 1971, 40). Instead of educating children based on their parents' social class, he advocated a "single type of formative school (primary-secondary) which would take the child up to the threshold of [her or] his choice of job, forming [her or] him during this time as a person capable of thinking, studying, and ruling - or controlling those who rule" (Gramsci 1971, 40). Gramsci advocated education as a way of releasing the power of Enlightenment individuals.

This stance on education was consistent with Gramsci's decidedly liberal image of the individual. For him every person was an intellectual and a philosopher, even though most rarely actualized those roles, and society could maximize democracy by making every individual intellectually capable of governing. He believed individuals with "an active intelligence" would reorder the basic material of the class-constrained education in their own way and become "organic intellectuals," capable of leading others through education (Gramsci 1971, 36). As Henry Giroux argues, "The project of liberal education for Gramsci was wedded to the fundamental socialist principle of educating the complete person, rather than the traditional concern with educating specialists, technocrats, and other professional experts" (Giroux 1999, 15). Both Freire and Gramsci believed in the inherent ability of individuals to break free of the structural impediments built into the educational system and understand their oppression (Mayo 2000). Organic intellectuals actualize their agency through the act of leading and educating the masses to be "legislators" (Gramsci 1971, 266).

To the degree that education prepares people to see class oppression and act in the interest of the oppressed, Gramsci allows for the liberal education of my privileged students. Like Freire, Gramsci is certain those injustices are organized along class lines. Given my own interlocking positions of privilege, I am significantly less certain I know how my students will interpret the patterns, justifications, and power of the multiple and varied hierarchies we study. bell hooks is also suspicious of the overriding importance Freire and Gramsci give to class cleavages. Like Freire and unlike Gramsci, however, she argues that underprivileged social positions of provide privileged analytical positions with respect to understanding and effectively challenging systems of oppression.

bell hooks

In Teaching to Transgress, (1994) bell hooks issues an evocative call to arms in service of a pedagogical program designed "not merely to share information but to share in the intellectual and spiritual growth of our students" (hooks 1994, 13). Her "engaged pedagogy" is a set of practices designed to change traditional classroom dynamics, to expose students to oppressive social arrangements, and to empower them to carry out changes to those systems. Her descriptions of 
these approaches are, like her teaching, noticeably self-referential, intimate and reflective, using stories of personal experiences that accentuate her own identities (Florence 1998). This personal quality makes her ideas about the relationship between students, professors, privilege and pedagogy particularly provocative.

Like the other two theorists, hooks rejects the "all-knowing" professor/passive students model of education because it divorces knowledge from the people who participate in its re-creation and obscures the political context in which professors are empowered and social hierarchies are normalized (hooks 1994, 139). The practices of engaged pedagogy can transform the project of a college education by creating an exciting community of exploration and learning for both students and professors. Education is not the transfer of timeless and universal bits of truth, but the creation of knowledge in the sense that it exists in places and in ways that it did not exist before. For hooks, education is designed to acculturate students to the dominant value/power structures into which they were born, but it fulfills its promise of freedom when teaching enables students and professors to break the constraints of those structures.

The classroom, with all its limitations, remains a location of possibility. In that field of possibility we have the opportunity to labor for freedom, to demand of ourselves and our comrades an openness of mind and heart that allows us to face reality even as we collectively imagine ways to move beyond boundaries, to transgress. This is education as the practice of freedom (hooks 1994, 207).

The engaged part of engaged pedagogy is student participation in the act of knowledge creation. hooks expects her students to share their experiences and perspectives as observers of and participants in social reality. That social context is often imagined as manifested in people's bodies, a metaphor for their social identities. hooks argues for "bringing bodies into the classroom" and being very upfront about the racist and patriarchal baggage that those bodies drag in with them (hooks 1994, 138). This commitment to hearing from students is the heart of a pedagogy dedicated to disrupting existing social systems. "To engage in dialogue is one of the simplest ways we can begin as teachers, scholars, and critical thinkers to cross boundaries, the barriers that may or may not be erected by race, gender, class, professional standing, and a host of other differences" (hooks 1994, 130). The resulting diversity of opinion entails turning the classroom into a site of conflict and antagonism. Professors need to develop strategies to deal with this conflict, and a passion to use it to build community in the classroom. "When we, as educators, allow our pedagogy to be radically changed by our recognition of a multicultural world, we give students the education they desire and deserve. We can teach in ways that transform consciousness, creating a climate of free expression that is the essence of a truly liberatory liberal arts education" (hooks 1994, 44).

hooks is committed to the process of a liberal education and to multicultural diversity in the classroom, but these are intermediate goals in the service of the destruction of racism and patriarchy. This project is quite personal, and hooks claims a privileged position within the project because of her identity and experiences of oppression. "The pain of her marginality, the pain her writings so clearly manifest, is truly unique. One has to have experienced marginality to fully appreciate the significance of its negation and the impact of subjugation" (Florence 1998, xix). hooks is recruiting students to help her change racism and patriarchy and particularly wants non-white, non-masculine, non-wealthy students. The "experience" she is seeking to incorporate into her classroom, therefore, is experience of racial, gender and class oppression. This practice has caused some to criticize her work as the epitome of a "cult of victimization" (Wallace cited in Florence 1998, xxiii).

While recognizing that the complexity of privilege extends beyond racial and gender identity categories, when hooks condemns the practice of essentializing identity, she means race and gender 
(hooks 1994). In fact, hooks wants to use essentialism to mobilize political movements against racism and patriarchy. From the perspective of political identity, politics is about marketing claims that coalesce groups of actors who feel compelled to act (e.g. vote) as proper members of that group. While hooks acknowledges in principle that a liberal education should allow students to problematize all categories of hierarchical identity, she also resists mobilizing identity categories other than race and gender because to do so would dilute the identities that would hold together her political movement against racism and patriarchy. hooks owns these political projects because of her personal experiences of racial and gender oppression.

Personal experiences of oppression are important enough to hooks that she casts doubt on the ability of those in privileged positions to understand or teach them, effectively questioning whether I and many of my students can fully confront these oppressive systems. Indeed, many of her anecdotes pit her against White Male Professors (see hooks 1994, 39). She argues that I would teach certain courses not just differently from a Black Woman, but worse, because I lack the experiences and the passion she deems necessary to understanding and conveying certain ideas (hooks 1994, 90). Being a White Cisgender Male undoubtedly affects how I lead my students in political projects of race and gender, and it is also reasonable for hooks to advocate for the relative effectiveness of her pedagogy. Additionally, hooks does leave room for me to teach using her ideas, arguing that the chance to undo systems of domination is worth the risk that "the crossings of the powerful into the terrains of the powerless will ... perpetuate existing structures" (hooks 1994, 1301). I feel, however, neither incapable of passion for confronting privilege/oppression nor ineffective in helping my students do so. Our different experiences of structures of oppression may well lead hooks and me to enact different political projects or to enact the same political projects differently, but there is nothing wrong with that. Negotiations between different political projects are part of the liberal dialectic that hooks and I both celebrate.

What troubles me about the pedagogies of Freire, Gramsci and hooks is the certainty of the political projects they establish as goals of their interactions with their students. There is a difference between teaching to empower students to carry out change and teaching to tell them what to change. Freire, Gramsci and hooks all do more of the latter than I am comfortable with. It may be that my discomfort with these authors' certainty about their own diagnoses of and solutions to oppression is some kind of unconscious defense of my privileges. But the explicit goals of my teaching are to help students recognize systems of privilege and empower them to remake them. Freire argues that the oppressed are best positioned to redesign social systems to end oppression, which means that hooks may indeed be better positioned to lead political movements to end racism and patriarchy. However, if the goals are 1) to teach globally privileged students to understand the many interlocking global systems of privilege (including but not limited to race, gender and class) without inspiring defensiveness and 2) to empower all students to work on behalf of changing those systems, teaching from a position of privilege may have certain advantages. The anthropologist Clifford Geertz (1973) described ethnography as the art of translating one culture's reality into terms that makes sense of it for those in another cultural reality. Often the best person to make that translation is not the one who understands the foreign culture best, but rather the one who understands the symbols and metaphors that will make sense of it to the receiver. This analogy gives me hope that my position may provide some purchase on teaching my globally privileged students about all kinds of privilege, lessons that should be an integral part of a twenty-first century liberal education. 


\section{Global Identities of Privileged Students}

While processes that mark liberal agents (analysis, critical thinking, collective problem solving) are much more integral to a liberal education than the content of any specific class or discipline, I have found the intersection of identity and globalization to be effective material for preparing globally privileged students to be effective participants in our contemporary liberal society. In addition to briefly expanding on those claims, I also want to venture some proposals for the processes globally privileged professors might build explicitly into their course goals when teaching such content to globally privileged students. I argue in the conclusion that this content and these processes embody the values of critical pedagogy Freire, Gramsci, hooks, and I all advocate.

\section{Global identities as content}

One challenging topic at the intersection of identity and globalization is identity itself. Our culture generally presents individuals' identities as largely settled, although they may evolve as individuals accumulate accomplishments and master knowledge and skills. This modern, Freudian understanding of identity makes each person a unique, essentially consistent, monad (Burkitt 1991; Kratochwil 1996) and students generally assume that they "own" these identities. I challenge these assumptions by asking students to think of their identities as the aggregate list of innumerable identity labels, each of which carries an implicit claim that all individuals so labeled are similar in some important way (Singer 1987; Frueh 2003). Constitutive of this similarity is a complementary assertion that all those so labeled are at the same time different from all those to whom the label does not apply (Connolly 1991). Being identified as a "college student" has meaning because of the social expectations associated with being in that group and because of the differentiation it provides from those who are not. While in our culture individuals may "own" the lists of labels that describe them, the meaning of each constituent label is "owned" by society and largely beyond the power of an individual to control. The list of labels is arranged in a continuously shifting hierarchy depending on what descriptions are most important to a given interaction. No one is always acting as a student, but sometimes as a sibling or an employee or a restaurant customer. We can pay attention to particular labels and to the types of interactions that evoke them. In what types of situations are, for example, national identities important? The assertions of similarity/difference encoded into identity labels are, as I asserted above, how we organize and justify inequalities and how we know which actors should be privileged and which should not. Breaking identity up into its complexity helps because it complicates the dualistic narrative of oppressed/oppressor and helps all students see ways in which they both benefit from and suffer as a result of systemic inequality.

Another way in which the concept of global identities challenges privileged students to confront systems of privilege is by exposing them to the broadest scope of human difference and inequality. The changes in relationships, technologies and attitudes generally grouped under the term globalization mean that an increasing number of their interactions and decisions will be global in important ways. While globalization can accentuate our common humanity and make distant "others" seem more similar, it can also draw attention to all the ways in which "our" way of doing things is not the only way. More global interactions can unsettle and problematize traditional systems humans have invented for organizing politics and sorting "us" from "them" (Croucher 2004). National identities in particular are becoming more problematic as states lose the power to manage interactions within their territories, and people switch at least some of their allegiances to alternate networks that are more global in scope, some as seemingly mundane as Amnesty International, or iPhone users or Coke drinkers (Mathews 2000; Nederveen Peiterse 2015). The increased relevance of other societies can provide professors with ways to confront domestic problems without eliciting the defensiveness some students exhibit when confronted with their own privilege. For example, I have found it much easier to discuss the concept of structural racism by 
starting the conversation describing the dynamics of South African apartheid before bringing the conversation around to all the similarities with the history of American racism. And students must confront the reality of their own economic privilege in light of global poverty statistics and what it takes to be part of the global 1\%. As the dynamics of globalization alter limited and isolated frames of reference, professors have opportunities to challenge their students to negotiate new understandings of those relationships. Such understandings will only become more important to what it means to be a competent and informed citizen of an increasingly integrated world.

\section{Global identities in processes}

Understanding the social nature of one's self and positioning that self in a globalizing world are comparable to any number of other projects that typically make up undergraduate General Education programs. What makes such courses (and such General Education programs) appropriate components of a liberal education is a focus on developing in students the ability to carry out processes necessary to be fully competent liberal individuals in a liberal society. These processes are summarized in the developmental model of engaged learning advocated by Hodge, Baxter Magolda and Haynes (2009). Their model is designed to move students from uncritical acceptance of authority to

increasingly complex meaning-making structures in the epistemological, intrapersonal and interpersonal dimensions. For example, students who learn to analyze knowledge claims critically and to generate their own ideas have achieved a self-authored epistemological stance. Yet to achieve effective practice in life, they must also have a self-authored intrapersonal structure that enables them to register disagreement and to argue for their perspectives. In addition, they need a self-authored interpersonal structure that values standing up for one's beliefs over gaining affirmation from others (Hodge et al. 2009, 18).

The concept of an author carries significance for creativity and agency (Foucault 1984) that students recognize as empowered responsibility. Educational experiences that consciously and explicitly include these broader learning outcomes create opportunities for students to move beyond acquiring disciplinary knowledge to engaged liberal learning. In my experience, courses focused on global identities can provide rich opportunities for students (particularly privileged students) to practice the processes of perspective taking, critical reading and analysis, public discourse and self-authorship.

Understanding global identity/difference means confronting surprising cultural and economic variations from the full breadth of contemporary human experience. Surprise can lead to confusion and confusion can motivate students to figure things out for themselves. When motivated students are given the resources and encouragement to explore "How could they think that is normal?" as a sincere rather than dismissive question, they practice holding and evaluating multiple perspectives, which is an important step toward embracing the constructed, socially determined nature of the knowledge that has so much power over their own lives. As the codes that organize and manage the relations between self and other, us and them, and similarity and difference, identity labels are integral to how students confront foreign values, actions and justifications. Sincerely investigating the complexity of those dissonant perspectives necessarily involves exploring the systems of meaning they have been using to interpret events, actors and relationships.

While a number of students experience these explorations in intensely personal ways, the classroom provides opportunities for all students to participate in public discourse over issues as important as their identities, power and privileges. I teach politics, which is the processes communities use to decide what is important and what to do about it. Classroom discussions about 
identity labels, the privileges they contain and the social arrangements that support them give students practice doing politics, and typically, students are happy to share the burden of their confusion with others confronting similar challenges. Students who might not otherwise contribute to such discussions can be empowered by a number of pedagogical strategies, such as using cooperative learning base groups (Johnson et al., 1998), having students post reading reflections to the class, and working through class-specific ground rules for carrying out often difficult and contentious conversations in respectful, "civil" ways. While students typically have no problem recognizing the qualities that make each of them unique, using such perspectives and techniques to study their global identities can recalibrate their sense of belonging in a way that bestows new responsibilities for the meaning of their shared identity.

For many students, especially those new to a liberal education environment, practicing the processes of perspective taking, critical analysis and public discourse/group problem solving is challenging enough for any semester. But the unsettled nature of political topics provide numerous opportunities to incorporate pedagogies that challenge students who are ready for developmentally more sophisticated process of self-authorship. The discussion of identities and power is conducive to shifting students' relationship to knowledge from receivers of knowledge to participants in the negotiations that determine which ideas should be classified as knowledge. Not only are they authorized to contribute to the discourse about whether a particular knowledge claim should be accepted, they can also author their own knowledge claims about global politics and submit them for evaluation in ways recognized by the scholarly community. The idea that individuals are creative agents and authors of unique ideas/knowledge is integral to American culture, but many students have a difficult time conceptualizing themselves as authors or scholars in educational contexts. As with perspective taking, critical analysis and public discourse, students benefit from transparency professors explicitly and repeatedly drawing student attention to the processes and educational goals of an assignment (McNair 2016, 3) - helps students to internalize the vocabulary of authorship and recognize when they are working through these same processes in other aspects of their education. While every student will not achieve self-authorship in every course, when combined with a discussion of privilege, using these processes to study global identities can have a profound effect on how students understand their personal goals, the values of the society into which they were born and their relationships to the others who share their planet.

\section{Conclusion}

The three scholars of critical pedagogy examined above all want to undermine existing systems of privilege by teaching students about those systems in ways that empower and inspire them to create change. Despite my own privileges and the fact that the career path I have chosen means that I teach the world's privileged, I share that same goal. While all three authors are skeptical about including me and (to varying degrees) my students in their projects, I believe it is wrong to assume that the privileged are either incapable of understanding the contradictions of those system of privilege or any less offended by them once they do. The best way to insure that actions of the privileged support existing arrangements of inequality is to leave them unaware and uncritical of the rationalizations and cultural assumptions that have surrounded them since birth. Letting the students come to their own conclusions about these arrangements is not without dangers, of course. Students may decide, on reflection, that they want to live in a racist world. Discussion of gender may only further entrench patriarchal or cisgender privilege. It may be that encounters with the global other only increase xenophobia and religious intolerance. But that has not been my own experience, and I have faith that oppression is less severe in societies where all citizens participate in an open and contentious democratic process. Democracy works best if all citizens, privileged or not, learn and 
practice analyzing multiple perspectives, sorting through complex issues with others and authoring their own ideas, perspectives and solutions.

A liberal education should be defined by its ability to create environments in which students gain expertise in such processes. In our globalizing world, such an education also needs to complicate the relationship between students' personal lives and the lives of the seven and a half billion other humans with whom their lives will increasingly intersect. Defining identity as a multitude of shifting, socially-defined identity labels complicates the dualism of Freire's oppressor/oppressed antinomy and means that students have more responsibility for thinking through who they are in their interactions with others. Making identities global means their critical reflections on their own positions within the system must take into account the widest range of human diversity. The global is not just local; it is also personal. To the degree that students embrace their global identities, their selves and their relationships become more complicated and it becomes harder for them to be complacent participants in the power systems into which they were born. The pedagogy of global identities focuses both professor and student attention on content and processes that serve the goals of critical education.

I educate individuals to be successful in a late-modern, liberal society. I have profound objections to both modernity and liberalism. But the social structures into which my students graduate will measure them by late-modern, liberal standards. So I have decided that the teaching/learning in my courses should prepare students to succeed in that context. I think this is fair to the students and parents; it is what my college tells them we will do. However, the main reason I am willing to adopt this overarching goal of producing effective citizens of a democratic/capitalist society is because the teaching/learning I really want to happen is congruent with some of the rhetorical justifications of modern liberalism (as opposed to its lived reality). Agency is the rhetorical core of liberal individualism. The overarching goal of teaching/learning in my courses is to call liberalism's bluff about agency, to empower and set loose the unique creative mind of each teacher/student.

Lastly, I want to return to the argument that who I am can help students confront their positions within these social arrangements of profound inequality. I do not question the ability of Freire's oppressed, Gramsci's organic intellectuals, and hooks' victims of racism and patriarchy to implement pedagogical strategies that effectively inspire their oppressed students to implement social change. But because of our positions in the system, teachers like me also have qualifications that enable us to translate to the privileged both the experiences of the oppressed and their critiques of the system as a whole. My privileged identities mean students may attribute to me some authority to speak on behalf of social arrangements in ways that might inspire defensiveness if the criticisms felt like personal attacks. By owning and unsettling my unearned advantages, including those provided by the professor/student relationship in the classroom, I believe I can create environments in which leaders of social change may emerge, regardless of the privileges with which they arrive.

\section{References}

Burkitt, Ian. 1991. Social Selves: Theories of the Social formation of Personality. London: Sage.

Connolly, William. 1991. Identity/Difference: Democratic Negotiations of Political Paradox. Ithaca: Cornell UP. 
Croucher, Sheila. 2004. Globalization and Belonging: The Politics of Identity in a Changing World. Lanham, MD: Rowman and Littlefield.

Entwistle, Harold. 1989. Antonio Gramsci: Conservative Schooling for Radical Politics. Boston: Routledge and Kegan Paul.

Florence, Namulunda. 1998. bell hooks' Engaged Pedagogy: A Transgressive Education for Critical Consciousness. Westport, CN: Bergin and Garvey.

Foucault, Michel. 1984. "What is an Author?" in The Foucault Reader, edited by Paul Rabinow. New York: Pantheon Books, pages 101-120.

Freire, Paulo. 1968. Pedagogy of the Oppressed, translated by Myra Bergman Ramos. New York: Herder and Herder.

Frueh, Jamie. 2003. Political Identity and Social Change: The Remaking of the South African Social Order. Albany: SUNY Press.

Frueh, Jamie, David Blaney, Kevin Dunn, Patricia Goff, Eric Leonard and Simona Sharoni. 2008. "Political Beliefs and the Academic Responsibilities of Undergraduate Teaching," Journal of Political Science Education, vol4, no4 (December) 447-462.

Geertz, Clifford. 1973. The Interpretation of Cultures. New York: Basic Books.

Giroux, Henry A. 1983. Theory and Resistance in Education: A Pedagogy for the Opposition. South Hadley, Mass.: Bergin \& Garvey.

Giroux, Henry A.1989. Schooling for Democracy: Critical Pedagogy in the Modern Age. London: Routledge.

Giroux, Henry A. 1999. "Rethinking Cultural Politics and Radical Pedagogy in the Work of Antonio Gramsci." Educational Theory (vol 49, Issue 1) accessed through Academic Search Elite, http://search.ebscohost.com/login.aspx?direct $=$ true\&db=afh\&AN=1720839\&site=ehostlive.

Giroux, Henry A. 2011. On Critical Pedagogy. New York: Continuum International Publishing Group.

Gramsci, Antonio. 1971. Selections from the Prison Notebooks, edited and translated by Quintin Hoare and Geoffrey Nowell Smith. New York: International Publishers.

Hirsch, E.D. 1996. The Schools We Need (New York: Doubleday).

Hodge, David C., Marcia B. Baxter Magolda and Carolyn A. Haynes. 2009. "Engaged Learning: Enabling Self-Authorship and Effective Practice.” Liberal Education (Fall): 16-23.

hooks, bell. 1994. Teaching to Transgress: Education as the Practice of Freedom. New York: Routledge.

Johnson, David W., Roger T. Johnson, \& Karl A. Smith. 1998. "Cooperative Learning Returns To College: What Evidence Is There That It Works?" Change (July/August 1998): 27-35. 
Kenny, Charles. 2012. "We are All the 1 Percent," Foreign Policy February 12. Accessed online at http:// foreignpolicy.com/2012/02/27/were-all-the-1-percent/

Krank, H. Mark and Stanley Steiner. 2000. “A Pedagogy of Transformation: An Introduction.” In Freirean Pedagogy, Praxis, and Possibilities: Projects for the New Millennium, edited by Stanley F. Steiner, H. Mark Krank, Peter Mclaren, and Robert Bahruth, pp ix-xiii. (NY: Farmer Press).

Kratochwil, Friedrich. 1996. "Is the Ship of Culture at Sea or Returning," in The Return of Culture and Identity in IR Theory, edited by Yosef Lapid and Friedrich Kratochwil. Boulder: Lynne Reinner.

Mathews, Gordon. 2000. Global Culture/Individual Identity: Searching for Home in the Cultural Supermarket. NY: Routledge.

Mayo, Peter. 2000. "Synthesizing Gramsci and Freire: Possibilities for a Theory of Transformative Adult Education," in Freirean Pedagogy, Praxis and Possibilities: Projects for the New Millennium editied by Stanley Steiner, H. Mark Krank, Peter McLaren and Robert Bahruth pp 249-283. (New York: Falmer Press).

McLaren, Peter. 1989. Life in Schools: An Introduction to Critical Pedagogy in the Foundations of Education. New York: Longman.

McLaren, Peter. 1997. "Critical Pedagogy." Teaching Education 9 (1): 1.

McLaren, Peter. 2000. "Paulo Freire's Pedagogy of Possibility." In Freirean Pedagogy, Praxis, and Possibilities: Projects for the New Millennium. Stanley F. Steiner, H. Mark Krank, Peter McLaren, and Robert Bahruth eds. New York: Farmer Press. pp 1-21.

McNair, Tia Brown. 2016. "Designing Purposeful Pathways for Student Achievement through Transparency and Problem-Centered Learning." Peer Review. Vol 18. No. 1/2 (Winter/Spring 2016): 3-7.

Nederveen Pieterse, Jan. 2015. Globalization and Culture: Global Mélange. Lanham, MD: Rowman and Littlefield.

Pfnister, Allen O. 1984. "The Role of the Liberal Arts College: A Historical Overview of the Debates," Journal of Higher Education. Vol 55, no2 (March/April 1984): 145-170.

Schneider, Carol Geary. 2008. "Liberal Education Takes a New Turn" The 2008 NEA Almanac of Higher Education. Accessed at http://www.nea.org/assets/img/PubAlmanac/ALM_08_03.pdf.

Singer, Marshall. 1987. Intercultural Communication: A Perceptual Approach. Engelwood Cliffs, NJ: Prentice Hall. 